\title{
Analysis of evapotranspiration in the catchment of the Nurzec River, Poland using MODIS data
}

\section{Abstract}

The objective of this study is to analyse the spatial diversity and temporal variation of evapotranspiration in the catchment of the Nurzec River in the years 2001-2010. The study is based on MODIS images highlighting monthly accumulated values of evapotranspiration, Normalized Difference Vegetation Index (NDVI), and land use categories. Monthly evapotranspiration was calculated for the whole catchment as well as in different land use categories. The study focuses on assessing the relationship between the values of NDVI and evapotranspiration. The annual ET according to MODIS varied from $392 \mathrm{~mm}$ to $458 \mathrm{~mm}$. Deciduous broadleaf forests have a higher ET than other land use categories. The analysis shows a strong correlation between monthly ET and NDVI.

Keywords

Evapotranspiration $\cdot \mathrm{NDVI} \cdot \mathrm{MODIS}$ data $\cdot$ catchment of the Nurzec River

(C) University of Warsaw - Faculty of Geography and Regional Studies

\author{
Mateusz Ślązek \\ Department of Hydrology \\ Institute of Physical Geography \\ Faculty of Geography and Regional Studies \\ University of Warsaw \\ e-mail:mslazek@uw.edu.pl \\ Received: 16 May 2013 \\ Accepted: 7 January 2014
}

Introduction

Evapotranspiration $(E T)$ is one of the main water cycle processes of the river catchment. In some Polish catchments ET makes up as much as $70 \%$ of the precipitation and is an important element of the catchment water balance. An understanding of its quantities and dynamics is useful and necessary for environmentally-oriented water management, which helps to protect the environment. ET depends mainly on the following factors: meteorological variables, spatial diversity of soils and land use and vegetation.

Until relatively recently, evapotranspiration calculations were based mainly on point measurements available from meteorological stations. However, progress and development in remote sensing (RS) have created new opportunities for hydrology. RS has become an important tool for the assessment of evapotranspiration dynamics on different spatial and temporal scales (Calcagno et al. 2007). Nowadays, evapotranspiration can be estimated for larger areas, even where ground meteorological data are not available. A recently elaborated algorithm to estimate ET was proposed by the Numerical Terradynamic Simulation Group at the University of Montana (Mu et al. 2007; $\mathrm{Mu}$ et al. 2009). According to this algorithm, which is based on the Penman-Monteith equation, ET estimates are available across the entire globe, using imagery collected by the Moderate Resolution Imaging Spectroradiometer (MODIS) instrument aboard the satellites in NASA's Earth Observing System, Terra and Aqua (About MODIS, n.d.). Improvements to the MODIS Global Terrestrial Evapotranspiration Algorithm have resulted in the preparation of monthly ET estimates with $1 \mathrm{~km}$ resolution available online from NASA (Mu et al. 2011). These RS datasets are increasingly being used to provide spatial ET estimates on a regional scale (e.g. Jia et al. 2009; Velpuri et al. 2013) or as a first guess for medium-size catchments (e.g. Somorowska 2011).

In this study, the ET estimates from the MODIS Global ET Project were acquired and analysed in the lowland agricultural catchment of the Nurzec River, which is located in the eastern part of Poland (Fig. 1). The area of the catchment is about $2087 \mathrm{~km}^{2}$. The main objectives of this research are: (1) evaluation of spatial and temporal variability of ET in the Nurzec catchment in the years 2001-2010, (2) assessment of the temporal evolution of NDVI and (3) examination of the relation between $1 \mathrm{~km}$ ET and NDVI. Such a relation, described e.g. by the linear regression model, might be useful in further studies for ET downscaling to a finer spatial scale using high resolution NDVI data.

\section{Data and methods}

The following data from the MODIS project were acquired for 2001-2010: the ET product labelled 'MOD16A2', the NDVI product labelled 'MOD13A3' and the Land Cover product labelled 'MOD12Q1'. All these data were originally stored in a sinusoidal grid tiling system in HDF format. For this analysis, data were extracted and processed in the ArcGIS (version 9.3.1) for horizontal tile number 19 and vertical tile number 03 (h19v03). The images were re-projected to the Polish coordinate system (PUWG1992) and then the tool 'Extract by mask' was applied to extract ET images within the catchment boundary.

The product 'MOD16A2' represents the amount of transpiration by vegetation and evaporation from the canopy and soil surfaces. This is estimated by an algorithm based on the 


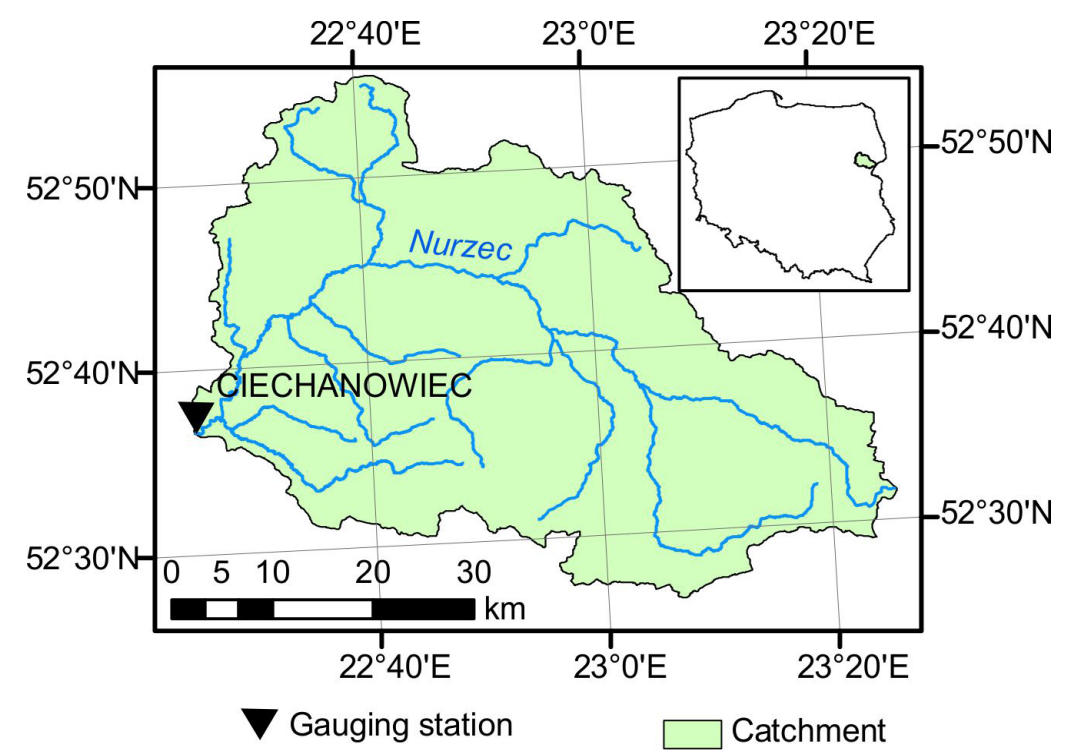

Figure 1. Location of the Nurzec River catchment

Penman-Monteith equation from the meteorological 8-day and 16-day remote sensing inputs (land cover, LAl, albedo, FPAR) and daily meteorological inputs (air pressure, air temperature, humidity and insolation) (Mu et al. 2011).

In order to identify land use categories within the analysed catchment, the product 'MOD12Q1' was applied, which is based on the land use classification compliant with the International Geosphere-Biosphere Program (IGBP), consisting of 17 land use categories, including eleven categories of natural vegetation, three categories of developed and mosaic lands and three categories of non-vegetated lands (King et al. 2004). In the Nurzec catchment there are seven land use categories distinguished: deciduous broadleaf forest, evergreen needleleaf forest, mixed forest, grassland, cropland, cropland and natural vegetation mosaic $^{1}$, and herbaceous and forest mosaic ${ }^{2}$.

As the Normalized Difference Vegetation Index is considered a good indicator of terrestrial vegetation productivity, it can be useful for the estimation of ET on a regional scale for hydrologic applications (e.g. Szilagyi et al. 1998; Szilagyi 2002; Haynes \& Senay 2012). In this study the relation between the ET and NDVI values was analysed by a simple linear regression model, using the equation $E T=a * N D V I+b$. Values of NDVI averages and monthly accumulated ET in the summer half of the year (May-October) were correlated for the period 2001-2010. The coefficient of determination $r^{2}$ was applied as a measure of the strength of interdependence between the two variables and calculated as follows:

$r^{2}=\left(\frac{\sum_{i=1}^{n}\left(E T_{i}-\overline{E T}\right)\left(N D V I_{i}-\overline{N D V I}\right)}{\sqrt{\sum_{i=1}^{n}\left(E T_{i}-\overline{E T}\right)^{2}} \sqrt{\sum_{i=1}^{n}\left(N D V I_{i}-\overline{N D V I}\right)^{2}}}\right)^{2}$

where:

$E T_{i}$ - evapotranspiration for the time step $i$;

$N D V I_{i}-$ NDVI for the time step $i$

$\overline{E T}$ - mean evapotranspiration;

$\overline{N D V I}-$ mean NDVI.

${ }^{1}$ A category defined in the IGBP classification as land with a mosaic of croplands, forest, shrublands and grasslands, in which no one component comprises more than $60 \%$ of the landscape.

${ }^{2}$ A category originally named as 'woody savanna' by IGBP. It is decrypted as land with herbaceous and other understory systems, and with forest canopy cover between 30 $60 \%$. The forest cover height exceeds 2 meters.
In order to prove how strong this relationship is, the correlation between ET and NDVI was calculated and analysed in two ways. First, average values for the whole catchment were analysed by correlating the mean monthly NDVI values with the monthly accumulated values of ET. Only the summer half-year (May-October) was considered, neglecting the winter half-year, when the NDVI values were close to zero. Secondly, values of ET and NDVI at pixels were correlated; the correlation between the corresponding pixels from the mean ET map and mean NDVI map for the summer half -year was examined. In both cases, Pearson's correlation coefficient $r$ was calculated.

Additionally, the digital terrain model (DTM) was prepared for the analysed catchment based on the data acquired from the Shuttle Radar Topography Model - SRTM (Jarvis et al. 2008).

Results and discussion

Temporal and spatial variability of ET

Annual, half-year and monthly accumulated values of ET in the Nurzec River catchment are presented in Table 1. In the decade 2001-2010 the annual accumulated values of ET range from $392 \mathrm{~mm} \mathrm{(2006)}$ to $458 \mathrm{~mm}$ (2002). The contributions of winter and summer half-year accumulated values of ET to the annual values are $13 \%$ and $87 \%$ respectively. Figure 2 shows that maximum monthly values of ET occur in summer (June and July) and minimum values in winter (November and December). There was an extremely high value in June 2008 (109 mm). Minimum values were recorded in December of 2001, 2005, 2009 and 2010 (even when rounded off to one decimal point, they are equal to zero).

Figure 3 presents the spatial distribution of annual accumulated values of ET. The highest values, recorded on the pixel scale, reach the approximate level of $700-800 \mathrm{~mm}$ in particular years and occur in forest areas and in the valley of the Nurzec River. This is highlighted by the dark blue colour. The possible explanation for such high annual water consumption is the presence of sources of water that support the ecosystems. This is possible in places with a shallow groundwater level, e.g. coincident with a riparian corridor. It is concluded that, in selected places, a riparian ET can be supported by a shallow aquifer, approaching the surface in the riparian zone. However, this should be proved by separate studies. Additionally, high rates of ET might also occur in places where tree roots are able to reach the water table and extract 
MISCELLANEA GEOGRAPHICA - REGIONAL STUDIES ON DEVELOPMENT

Vol. $18 \cdot$ No. $1 \cdot 2014 \cdot$ pp. 44-51 •ISSN: 2084-6118 • DOI: 10.2478/mgrsd-2014-0008

Table 1. Monthly, half-year and annual accumulated ET ( $\mathrm{mm})$ in the Nurzec River catchment in water years 2001-2010

\begin{tabular}{|c|c|c|c|c|c|c|c|c|c|c|c|c|c|c|c|}
\hline Year & Nov & Dec & Jan & Feb & Mar & Apr & May & Jun & Jul & Aug & Sep & Oct & Nov-Apr & May-Oct & Year \\
\hline 2001 & 0 & 0 & 2 & 5 & 20 & 31 & 76 & 80 & 94 & 73 & 26 & 14 & 57 & 362 & 419 \\
\hline 2002 & 2 & 6 & 3 & 7 & 22 & 32 & 83 & 99 & 98 & 69 & 29 & 10 & 71 & 387 & 458 \\
\hline 2003 & 1 & 4 & 2 & 6 & 18 & 24 & 73 & 95 & 95 & 51 & 32 & 11 & 55 & 358 & 412 \\
\hline 2004 & 0 & 0 & 5 & 6 & 20 & 24 & 50 & 81 & 94 & 73 & 36 & 13 & 55 & 348 & 402 \\
\hline 2005 & 2 & 0 & 0 & 5 & 16 & 28 & 61 & 93 & 93 & 65 & 35 & 16 & 51 & 362 & 413 \\
\hline 2006 & 1 & 1 & 4 & 5 & 12 & 29 & 52 & 93 & 82 & 52 & 45 & 15 & 52 & 340 & 392 \\
\hline 2007 & 0 & 0 & 2 & 5 & 18 & 29 & 73 & 100 & 85 & 71 & 38 & 12 & 54 & 380 & 434 \\
\hline 2008 & 1 & 0 & 1 & 9 & 19 & 28 & 66 & 109 & 91 & 66 & 29 & 12 & 59 & 372 & 431 \\
\hline 2009 & 4 & 0 & 1 & 2 & 14 & 30 & 65 & 81 & 96 & 71 & 42 & 9 & 51 & 363 & 414 \\
\hline 2010 & 0 & 0 & 5 & 3 & 25 & 28 & 63 & 96 & 97 & 71 & 30 & 13 & 61 & 369 & 430 \\
\hline mean & 1 & 1 & 3 & 5 & 18 & 28 & 66 & 92 & 93 & 66 & 34 & 13 & 57 & 364 & 421 \\
\hline
\end{tabular}

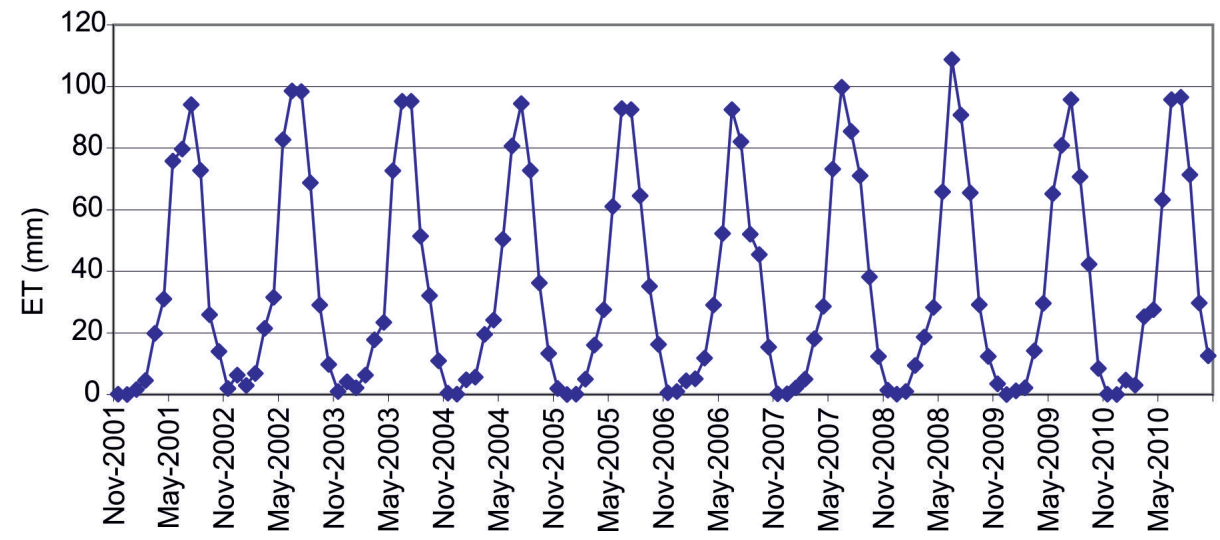

Figure 2. Monthly accumulated ET in the Nurzec River catchment in water years 2001-2010

groundwater. The smallest annual accumulated values of ET, within the range of approximately $170-250 \mathrm{~mm}$, are associated with places characterized by small NDVI values reflecting poor vegetation conditions.

The mean annual ET in 2001-2010 (421 mm) calculated from MODIS data was $17 \%$ lower than the ET estimated from the water balance equation $(511 \mathrm{~mm})$, assuming that the 10 year mean value of change in the catchment water storage was equal to zero. This may be a result of the uncertainty of discharge and precipitation data. Discharge uncertainty may be due to several reasons, including e.g. errors in stage and velocity measurements, extrapolation of the stage-discharge relationship beyond the measurement range, or cross-section change. Uncertainty in precipitation may be caused by the limited number of rain gauge stations. Areal precipitation was calculated by the Thiessen polygon method based on data from 5 rain gauge stations located within the catchment. Differences in the 10 year mean annual value between the stations amount to $74 \mathrm{~mm}$. Although the areal precipitation estimate $(P)$ might be slightly over- or underestimated, it is highly correlated with the ET-MODIS data. The relation for the summer half of the year was approximated by the following equation:
$P=0.85 * E T-M O D I S+26$. The Pearson's correlation coefficient equals 0.99 , indicating a strong correlation. Assuming that the $E T-M O D I S$ follows the rhythm of precipitation, further analysis has been conducted.

\section{Evapotranspiration across different land use}

Figures $4 \& 5$ present the temporal variability of monthly ET for distinguished land use categories. Mean monthly values of ET for the years 2001-2010 are shown in Figures 6 \& 7. It is concluded that deciduous broadleaf forests have higher ET values than other land use categories, with a mean annual ET equal to 488 $\mathrm{mm}$, and the highest mean monthly ET reaching $118 \mathrm{~mm}$ in July (Tab. 2, Fig. 6). In evergreen needleleaf forest and mixed forest, the mean annual ET was slightly lower (approximately $470 \mathrm{~mm}$ ). Relatively high values also occurred in croplands and the natural vegetation mosaic and grasslands where the mean annual ET was equal to $481 \mathrm{~mm}$ and $468 \mathrm{~mm}$ respectively, whereas the lowest values concern the croplands alone $(409 \mathrm{~mm})$. The highest monthly ET values occurred in July 2008 within the deciduous broadleaf forest category and reached $144 \mathrm{~mm}$ (Tab. 2, Fig. 4). 

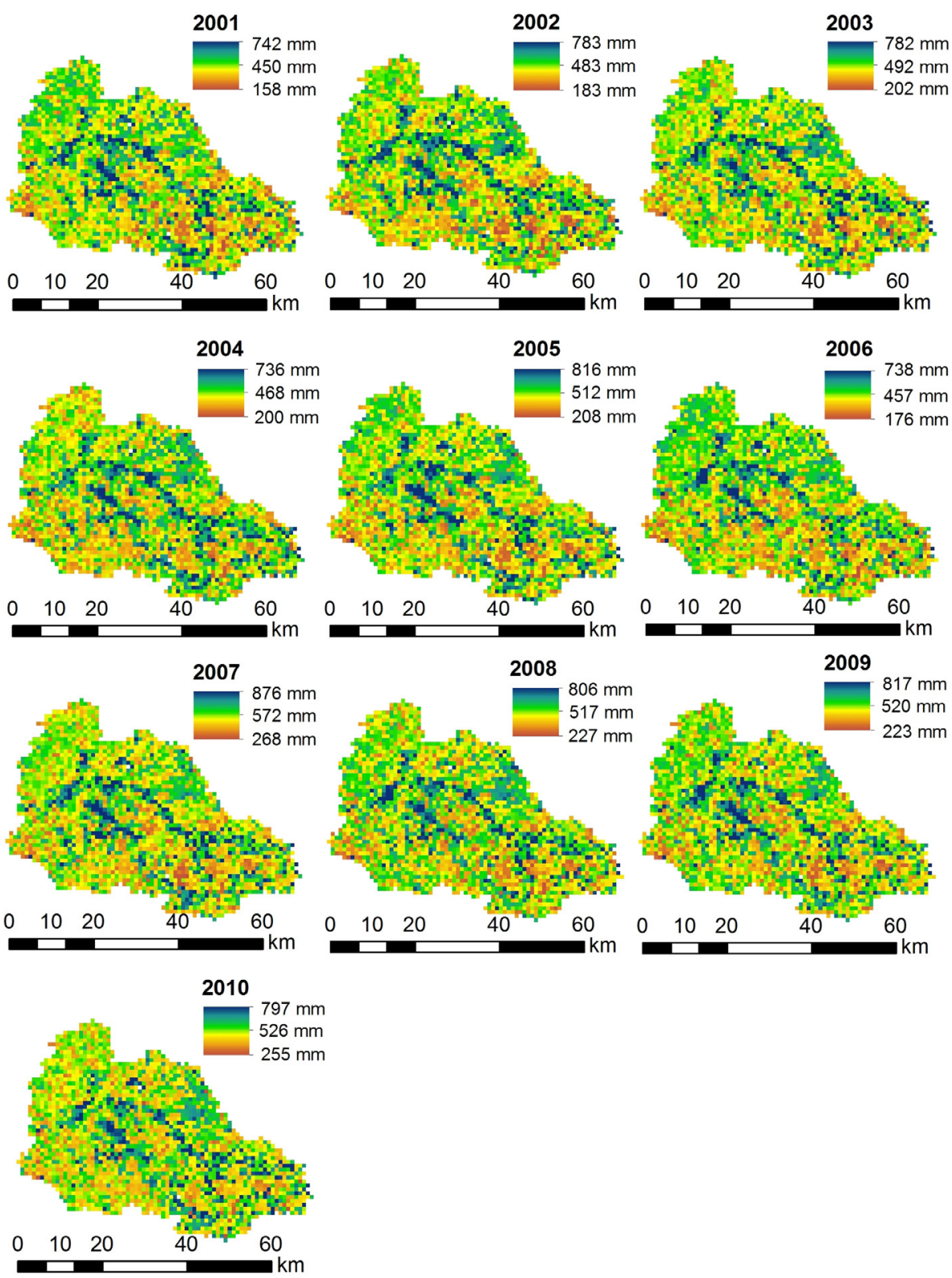

Figure 3. Spatial distribution of annual ET in the Nurzec River catchment in water years 2001-2010

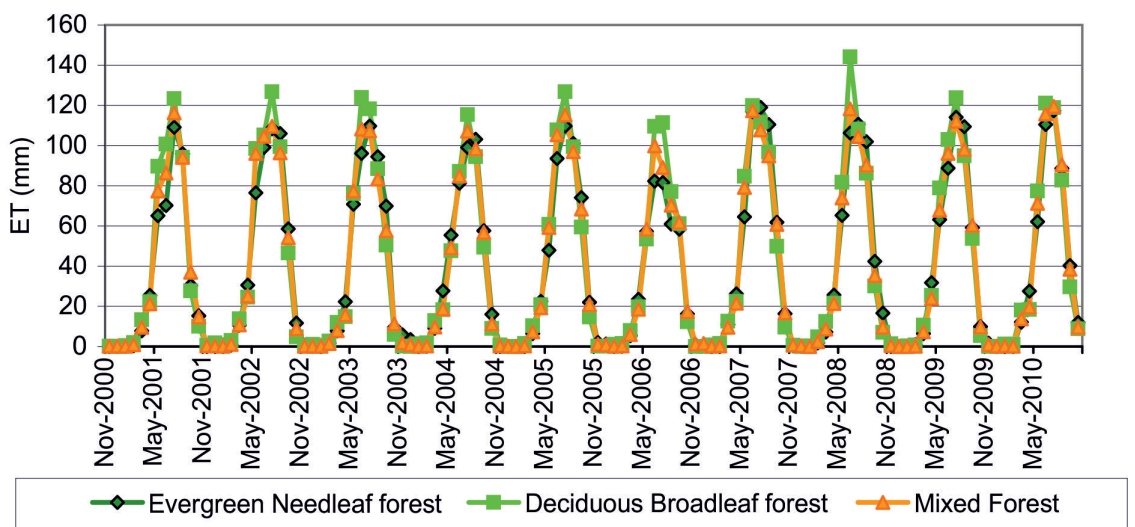

Figure 4. Monthly accumulated ET in water years 2001 - 2010 in the Nurzec catchment for three land use categories: deciduous broadleaf forest, evergreen needleleaf forest and mixed forest 


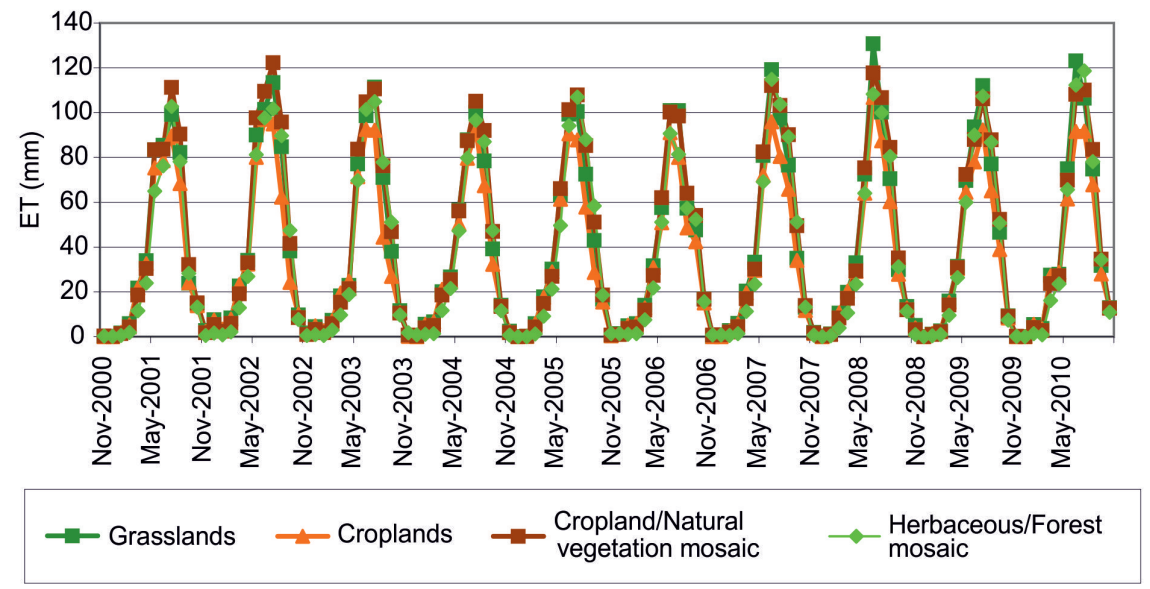

Figure 5. Monthly accumulated ET in water years 2001 - 2010 in the Nurzec catchment for four land use categories: grassland, cropland, cropland and natural vegetation mosaic, herbaceous and forest mosaic

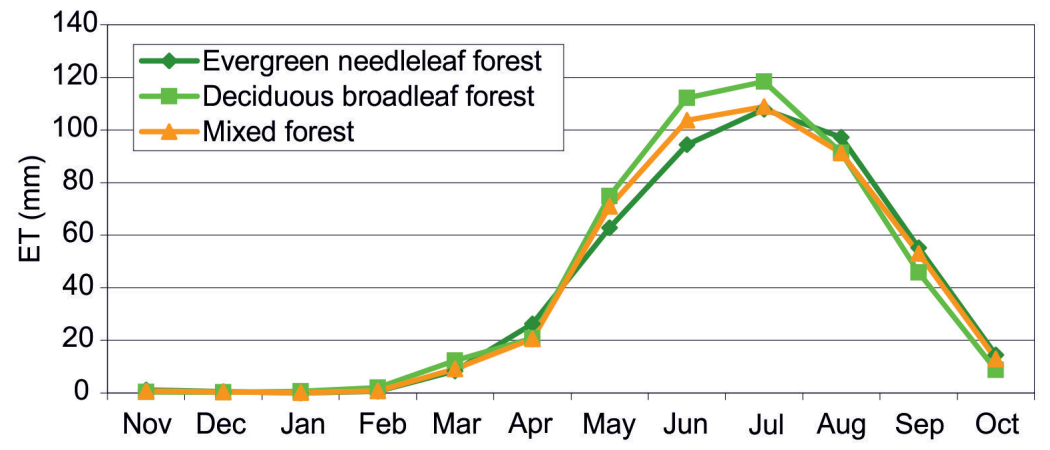

Figure 6. Mean monthly accumulated ET in the Nurzec catchment for three land use categories: deciduous broadleaf forest, evergreen needleleaf forest and mixed forest. Values averaged over water years $2001-2010$

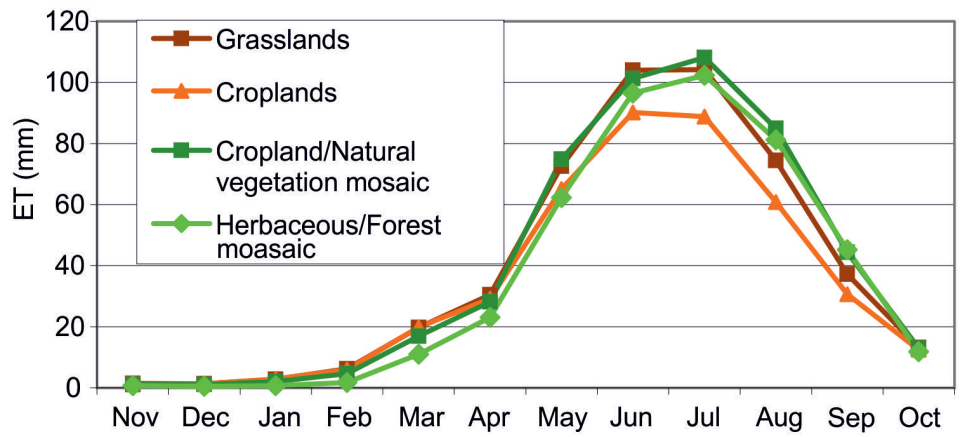

Figure 7. Mean monthly accumulated ET in the Nurzec catchment for four land use categories: grassland, cropland, cropland and natural vegetation mosaic, herbaceous and forest mosaic. Values averaged over water years $2001-2010$

Relation between evapotranspiration and NDVI

In order to examine the relation between ET and NDVI, firstly the monthly mean values of NDVI over the catchment were plotted together with the monthly accumulated values of ET versus time, depicting the approximate common temporal course (Fig. 8). Like ET, NDVI exhibits strong seasonal variability. While the maximum values for each year are quite similar (from 0.72 in June 2006 to 0.77 in July 2004), the minimum values are more varied (from 0.05 in February 2010 to 0.47 in January 2007). The lowest NDVI values are probably caused by the long presence of snow cover, when the NDVI values are close to zero. The similar temporal course of both the ET and NDVI plot lines indicates that the fluctuations of these variables are compatible (Fig. 8).

The relationship between mean monthly NDVI and ET values was also illustrated in the scatter chart in Figure 9. It can be seen that, in the months with the highest monthly accumulated values of ET (June and July), there are also the highest values of NDVI. The trend line was determined for the summer half-year values. The calculated Pearson's correlation coefficient is equal to 0.81 , 


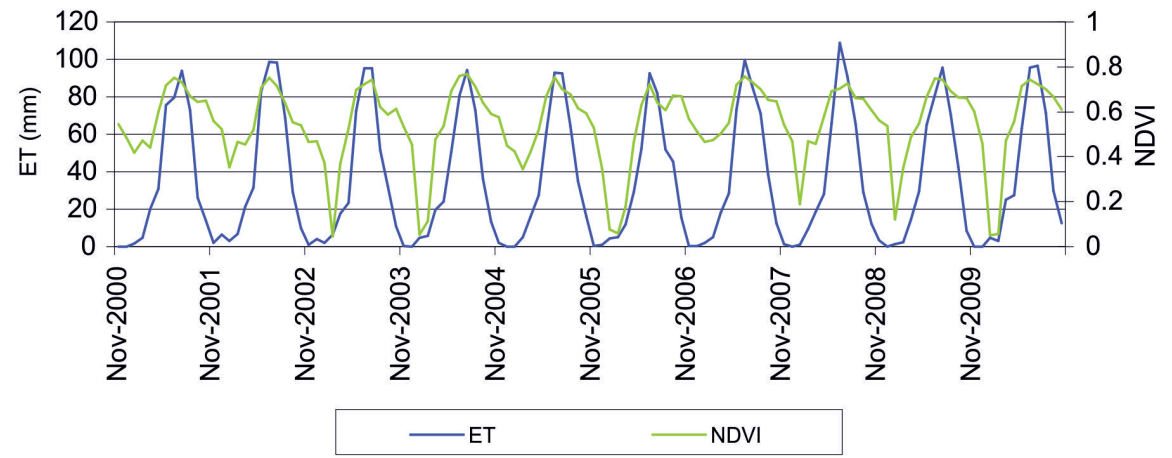

Figure 8. Monthly accumulated ET and mean monthly NDVI in the Nurzec River catchment in water years 2001-2010

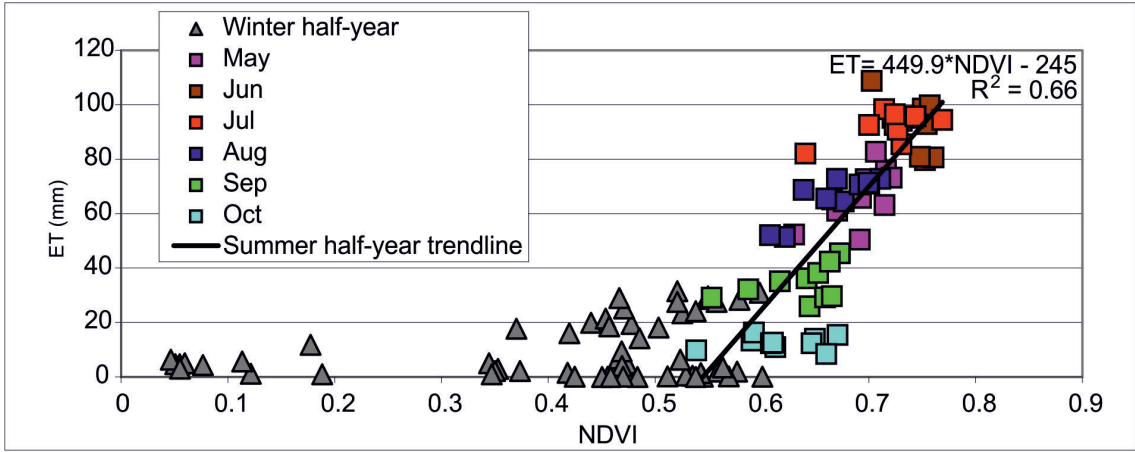

Figure 9. Relation between monthly accumulated ET and mean monthly NDVI in the Nurzec River catchment in water years 2001-2010

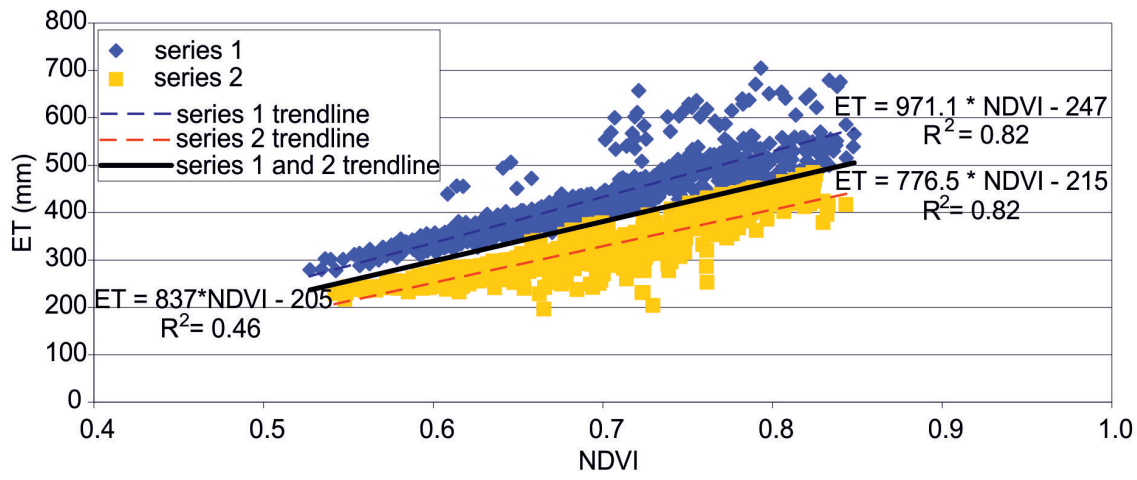

Figure 10. Relation between mean summer half-year ET and corresponding mean summer half-year NDVI for water years 2001-2010

which indicates a very strong correlation between the monthly accumulated ET and the mean monthly NDVI values in the Nurzec catchment in the years 2001-2010. In winter very low values of NDVI were caused by snow cover and little green vegetation corresponding to low values of ET, whereas in summer, good vegetation conditions occur simultaneously with high ET values. Thus, in this case it is proved that NDVI, as the vegetation vigour indicator, is in a linear response to evapotranspiration. Such a relation is location-dependent and requires an explanation on the pixel scale, discussed below.

The relation between mean summer half-year ET and NDVI values in 2001-2010 is shown in Figure 10. The ET-NDVI values are plotted for each pixel within the catchment boundaries. The Pearson's correlation coefficient for the whole set of data equals 0.68 , which indicates a strong correlation. On the chart, there are two clearly separated point groups. The correlation coefficient $(r)$ calculated separately for each series equals 0.91 , indicating a very strong correlation (Fig. 10). For the same value of NDVI, the corresponding value of ET, as detected by points belonging to series 1 , is higher than those ET values detected by series 2 . Presumably this can be caused by the availability of water for the ET process: higher in low-lying areas with shallow groundwater, and lower in the upland. In order to detect the location of pixels belonging to these two separate groups, a layer with the spatial distribution of points from series 1 and series 2 was overlaid on the DTM (Fig. 11). The location of the 1st series of pixels located mainly within low-lying areas of the catchment (with higher soil wetness), visible in the centre, may be a proof of higher ET. The relatively lower ET values detected by series 2 are found in pixels located in the upland areas in the north-eastern part of the catchment. However, the differences in ET in some pixels belonging to both series can't be explained by the 'dry' upland 
MISCELLANEA GEOGRAPHICA - REGIONAL STUDIES ON DEVELOPMENT

Vol. $18 \cdot$ No. $1 \cdot 2014 \cdot$ pp. 44-51 •ISSN: 2084-6118 • DOI: 10.2478/mgrsd-2014-0008

Table 2. Mean monthly accumulated ET $(\mathrm{mm})$ in the Nurzec catchment for selected land use categories averaged over water years 2001-2010

\begin{tabular}{|c|c|c|c|c|c|c|c|c|c|c|c|c|c|}
\hline Land use categories & Nov & Dec & Jan & Feb & Mar & Apr & May & Jun & Jul & Aug & Sep & Oct & Year \\
\hline $\begin{array}{c}\text { Evergreen } \\
\text { Needleleaf forest }\end{array}$ & 1 & 1 & 0 & 1 & 8 & 26 & 63 & 95 & 108 & 97 & 55 & 15 & 469 \\
\hline $\begin{array}{c}\text { Deciduous } \\
\text { Broadleaf forest }\end{array}$ & 0 & 0 & 1 & 2 & 12 & 21 & 75 & 112 & 118 & 91 & 46 & 9 & 488 \\
\hline Mixed forest & 1 & 0 & 0 & 1 & 9 & 21 & 71 & 104 & 109 & 91 & 53 & 13 & 473 \\
\hline $\begin{array}{c}\text { Herbaceous/ Forest } \\
\text { mosaic }\end{array}$ & 1 & 1 & 1 & 2 & 11 & 23 & 62 & 97 & 102 & 81 & 45 & 12 & 437 \\
\hline $\begin{array}{c}\text { Grasslands } \\
\text { Croplands }\end{array}$ & 1 & 1 & 3 & 6 & 20 & 30 & 73 & 104 & 104 & 75 & 37 & 13 & 468 \\
\hline $\begin{array}{c}\text { Cropland/Natural } \\
\text { vegetation mosaic }\end{array}$ & 1 & 1 & 2 & 5 & 17 & 28 & 75 & 101 & 108 & 85 & 44 & 13 & 481 \\
\hline mean & 1 & 1 & 1 & 3 & 14 & 26 & 69 & 100 & 106 & 83 & 45 & 12 & 461 \\
\hline
\end{tabular}

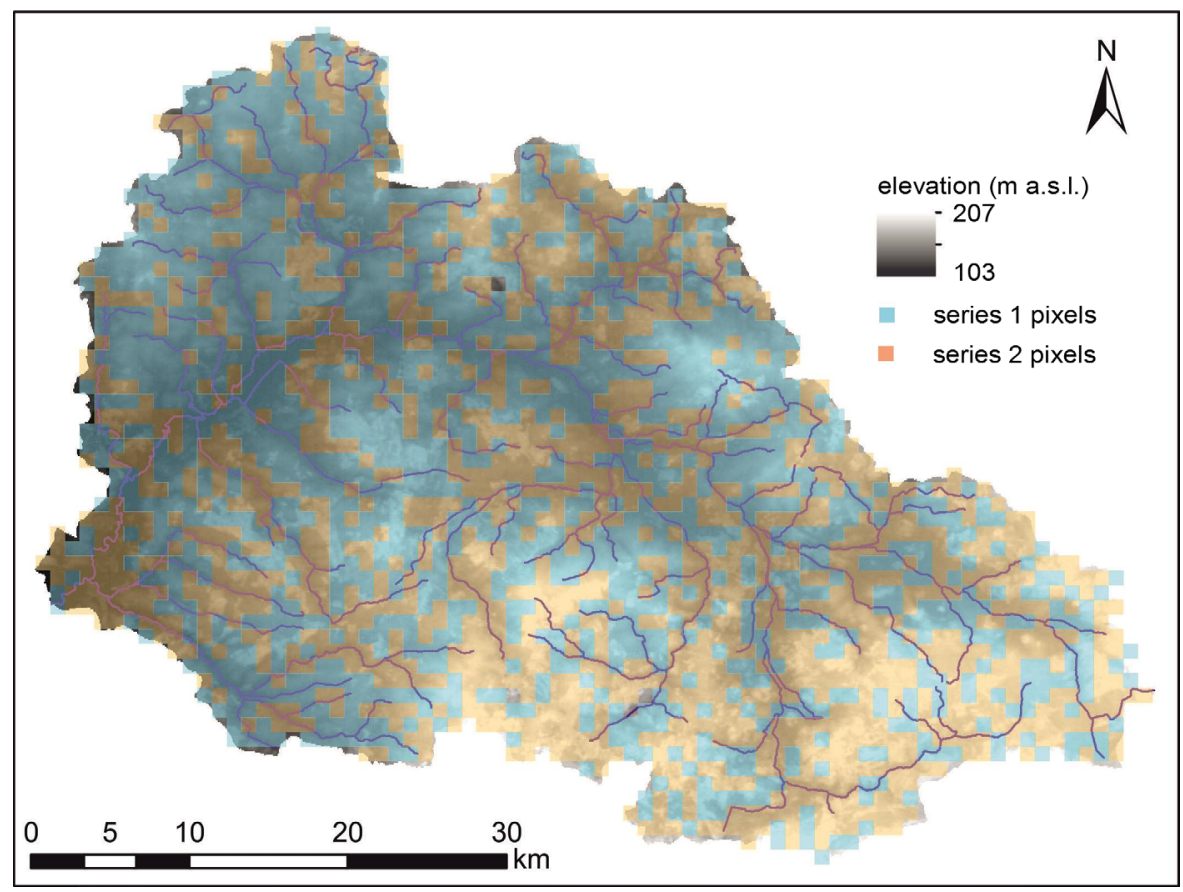

Figure 11. Spatial distribution of series 1 and series 2 in the Nurzec River catchment with the DTM background

or 'wet' low-lying location. This concerns pixels from both series in the north-eastern and south-western parts of the catchment. Thus, factor analysis, which is beyond the scope of this study, might further be a way to explain the group of main factors (vegetation, location, wetness, groundwater etc.) responsible for the spatiotemporal variability of ET.

\section{Summary and Conclusions}

1. The analysis of annual ET in the Nurzec catchment situated in the eastern part of Poland has indicated that $87 \%$ of the annual accumulated value of ET comes from the-summer half of the year. The mean annual ET for the years 2001-2010 was estimated at $461 \mathrm{~mm}$. This was $17 \%$ lower than the mean annual value calculated from the water balance equation, assuming a change in the catchment water storage equal to zero. Several sources of uncertainty could cause such a difference, including uncertainties in discharge and precipitation data. However, the summer half ET-MODIS is highly correlated with precipitation; as precipitation increases, evapotranspiration also rises, proving the reliability of the ET-MODIS data.

2. The analysis of the spatial variability of ET has shown that the highest ET occurred in forested areas, especially in deciduous forests. The mean annual ET in deciduous forest was $488 \mathrm{~mm}$. Relatively high values also occurred in croplands and the natural vegetation mosaic where the mean annual ET was equal to $481 \mathrm{~mm}$. In grasslands, a slightly lower ET value of 468 $\mathrm{mm}$ was found. The lowest ET, $409 \mathrm{~mm}$, occurred in croplands.

3. It was proved that in the analysed catchment, the NDVI, as the vegetation vigour indicator, is in a linear response to evapotranspiration for growing conditions in the summer half of 
the year. A strong correlation was found between ET and NDVI values, both for mean values for the whole catchment as well as for pixel data. Such a relation, described by the linear regression model, might be useful in further studies for ET downscaling to a finer spatial scale using high resolution NDVI data. It is catchment and location-dependent.

4. As the MODIS data have a medium resolution and pixels represent dominant land use and vegetation types, further studies are needed, beyond the scope of this research, to obtain higher resolution ET images, with pixels having more homogeneous land use. This is to be achieved with technologies converting images from a lower (coarser) to higher (finer) spatial resolution using statistically-based models or process-based numerical models (Ha et al. 2013).

5. Future steps of analysis might include factor analysis as a tool to explain the group of main factors, including vegetation, location, soil wetness, groundwater etc., responsible for the spatiotemporal variability of ET.

\section{Acknowledgements}

The author wishes to thank Urszula Somorowska, Ph. D., Associate Professor of the University of Warsaw, for all the support during this study as well as the Reviewers for their kind and helpful comments.

\section{References}

Calcagno, G, Mendicino, G, Monacelli, G, Senatore, A \& Versace, P 2007, 'Distributed estimation of actual evapotranspiration through remote sensing techniques', Methods and Tools for Drought Analysis and Management, vol. 62, pp. 125-147.

Ha, W, Gowda, PH \& Howell, TA 2013, 'A review of downscaling methods for remote sensing-based irrigation management: part I, Irrigation science, vol. 31, no. 4, pp. 831-850.

Haynes, JV \& Senay, GB 2012, 'Evaluation of the relation between evapotranspiration and normalized difference vegetation index for downscaling the simplified surface energy balance model, U.S. Geological Survey Scientific Investigations Report, vol. 8, pp. 2012-5197.

Jarvis, A, Reuter, HI, Nelson, A \& Guevara, E 2008, Hole-filled seamless SRTM data V4, International Centre for Tropical Agriculture (CIAT). Available from: <http://srtm.csi.cgiar.org> [26 may 2012].

Jia, L, Xi, G, Liu, S, Huang, C, Yan, Y \& Liu, G 2009, 'Regional estimation of daily to annual regional evapotranspiration with MODIS data in the Yellow River Delta wetland', Hydrology and Earth System Sciences, vol. 13, pp. 1775-1787.

King, MD, Closs, J, Spangler, S, Greenstone, R, Wharton, S \& Myers, M 2004, 'EOS Data Products Handbook, Volume 1', NASA Goddard Space Flight Center, Greenbelt, Maryland. Available from: <http://eospso.gsfc.nasa.gov/ftp_docs/data_ products_1.pdf> [10 April 2012].

MODIS Web, About MODIS, n.d. Available from: <http://modis gsfc.nasa.gov/about/> [15 October 2013].
Mu, Q, Heinsch, FA, Zhao, M, \& Running, SW 2007, 'Development of a global evapotranspiration algorithm based on MODIS and global meteorology data', Remote Sensing of Environment, vol. 111, pp. 519-536.

Mu, Q, Jones, LA, Kimball, JS, McDonald, KC \& Running, SW 2009, 'Satellite assessment of land surface evapotranspiration for the pan-Arctic domain', Water Resources Research, vol. 45. Available from: <http://onlinelibrary.wiley.com/ doi/10.1029/2008WR007189/full>.

Mu, Q, Zhao, M \& Running, SW 2011, 'Improvements to a MODIS global terrestrial evapotranspiration algorithm', Remote Sensing of Environment, vol. 115, pp. 1781-1800.

Somorowska, U 2011, 'Variable Patterns of evapotranspiration in a protected wetland catchment derived from MODIS data' in Ecohydrological methods in water management, eds JM Sawicki \& W Szpakowski, Wydawnictwo Politechniki Gdańskiej, Gdańsk, pp. 120-130.

Szilagyi, J, Rundquist, DC, Gosselin, DC \& Parlange, MB 1998, 'NDVI relationship to monthly evaporation', Geophysical Research Letters, vol. 25, pp. 1753-1756.

Szilagyi, J 2002, 'Vegetation Indices to Aid Areal Evapotranspiration Estimations', Journal of Hydrologic Engineering, vol. 7, pp. 368-372.

Velpuri, NM, Senay, GB, Singh, RK, Bohms, S \& Verdin, JP 2013, 'A comprehensive evaluation of two MODIS evapotranspiration products over the conterminous United States: Using point and gridded FLUXNET and water balance ET', Remote Sensing of Environment, vol. 139, 35-49. 